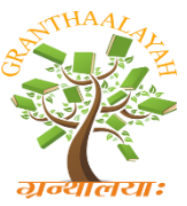

\author{
INTERNATIONAL JOURNAL OF RESEARCH - \\ GRANTHAALAYAH \\ A knowledge Repository
}

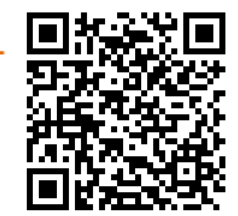

Science

\title{
STUDY ON PREVALENCE AND CYST CHARACTERIZATION OF HYDATIDOSIS IN CATTLE SLAUGHTERED AT WOLAYTA SODDO MUNICIPAL ABBATTIOR
}

\author{
Ataro Abera *1, Tamirat Teklebran ${ }^{2}$ \\ ${ }^{* 1,2}$ Department of Livestock and Fishery Resource Development, Dawuro Zone, Ethiopia
}

\begin{abstract}
A cross-sectional survey of bovine hydatidosis was conducted on local zebu cattle slaughtered at Wolayta Soddo Municipal Abattoir from November, 2012 to March, 2013 to determine the prevalence and cyst characterization caused by hydatid disease. No statistical significant variation was observed with regards to place of origin and age of the animals $(\mathrm{P}>0.05)$. After postmortem examination, hydatid cysts were collected and cyst characterization was conducted. Out of a total of 446 animals examined, 50(11.21\%) harboring one or more hydatid cyst. The result obtained from Postmortem examination indicated that the lung was the most commonly affected organ followed by liver. The involvement of lung, Liver, kidney, spleen and heart was found to be $50 \%, 26.92 \%, 5.77 \%, 9.62 \%$ and $7.69 \%$ respectively. From the total of 52 cysts counted, 14(26.69\%), 18(34.62\%), 20(38.46\%) were large, medium and small respectively and $5(9.62 \%), 35(67.31 \%)$ and $12(23.08 \%)$ were fertile, sterile and calcified respectively. Out 5 of fertile, $20 \%$ (1/5) were viable, all from the lung and higher liver calcification were observed.
\end{abstract}

Keywords: Abattoir; Cattle; Echinococcosis; Sterility; Wolayta Soddo; Prevalence.

Cite This Article: Ataro Abera, and Tamirat Teklebran. (2017). "STUDY ON PREVALENCE AND CYST CHARACTERIZATION OF HYDATIDOSIS IN CATTLE SLAUGHTERED AT WOLAYTA SODDO MUNICIPAL ABBATTIOR." International Journal of Research - Granthaalayah, 5(7), 60-78. https://doi.org/10.29121/granthaalayah.v5.i7.2017.2108.

\section{Introduction}

Ethiopia has the largest livestock population in Africa, with an estimated 49.3 million heads of cattle, 46.9 million sheep and goats, 7.55 million equines and 2.3 million camels (CSA, 2009). However, contribution from these huge livestock resources to the national income is disproportionately small, owing to several factors. Diseases are among the factors responsible for poor production and productivity. Parasitic diseases are considered as a major obstacle in health and product performance of livestock (Berhe, 2009). Among the parasite diseases, Echinicoccosis/hydatidosis is a zoonotic parasitic disease caused by the dog tapeworm Echinococcus and its larval stage, the hydatid cyst. This parasite is found worldwide and causes 
economic losses from the condemnation of affected organs and serious public health problems in certain parts of the world (Schantz, 1990).

Echinococcosis is a cyclozoonosis that requires two vertebrate hosts to uphold the life cycle. Humans can accidentally become intermediate hosts by ingesting the eggs of the tapeworm. While most cysts develop in the liver and lungs, other organs and tissue may become affected. At present, four species of the genus Echinococcus are recognized and regarded as taxonomically valid: E. granulosus (cystic hydatidosis), E. multilocularis (multivesicular hydatidosis), E. vogeli (polycystic hydatidosis) and E. oligarthrus (Soulsby, 1982).

These four species are morphologically distinct in both the adult and the larval stages. In addition, several different strains of E. granulosus and E. multilocularis are recognized. Only E. granulosus is the species most widely distributed throughout the world and primary concern in ruminants, including sheep and goats. E. granulosus has little host specificity with regard to intermediate hosts, hydatid cysts have been seen in a wide range of mammals, including domestic ruminants, camels, giraffes, pigs, equines, elephants, marsupials, hippopotamuses, and different types of deer as well as humans (FAO, 1982; Raush, 1986).

The development of strains may be a result of the fact that tapeworms are hermaphrodites, which reproduce themselves through cross- or self-fertilization. A single mutant can therefore, produce large genetically identical populations that differ from the original genus. These populations are referred to as strains (McManus and Smyth, 1986).

Echinococcus eggs contain an embryo that is called an oncosphere or hexcanth. The name of this embryo stems from the fact that these embryos have six hooklets. The eggs are passed through the feces of the definitive host and it is the ingestion of these eggs that lead to infection in the intermediate host. Hydatid cyst, which grows to about $5-10 \mathrm{~cm}$ within the first year and is able to survive within organs for years. Cysts sometimes grow to be so large that by the end of several years or even decades, they can contain several liters of fluid. Once a cyst has reached a diameter of $1 \mathrm{~cm}$, its wall differentiates into a thick outer, non-cellular membrane, which covers the thin germinal epithelium. From this epithelium, cells begin to grow within the cyst. These cells then become vacuolated and are known as brood capsules, which are the parts of the parasite from which protoscolices bud. Often times, daughter cysts will also form within cyst (John and William, 2006).

Echinococcus adult worms develop from protoscolices and are typically $6 \mathrm{~mm}$ or less in length and have a scolex, neck and typically three proglottids, one of which is immature, another of which is mature and the third of which is gravid or containing eggs. The scolex of the adult worm contains four suckers and a rostellum that has about 25-50 hooks (CDC, 2009) Echinococcus granulosus is primarily maintained through domestic and sylvatic life cycles. The life cycle is complex, involving two hosts and a free-living egg stage. The dynamics of the transmission of the parasite are determined by the interaction of factors associated with these two hosts and with the external environment (Permin and Hansen, 1994). In the definitive host the parasitic burden is determined by the number of protoscolices ingested. Natural resistance varies in dogs and there is evidence that acquired immunity develops slowly. This immunity is likely to affect the number of established worms (FAO, 1982; Soulsby, 1982). 
The Segments detached with the feces may perform rhythmic contractions and relaxations that assist egg-expulsion (FAO, 1982) and eggs may be dispersed over considerable distances away from the faeces. Since sheep generally avoid grazing near areas contaminated with dog feces, this dispersal mechanism enhances the chances of eggs being ingested by the grazing animals. This has an important epidemiological implication since a single dog can thus infect many sheep over a wide area (Gemmell and Lawson, 1986). It has also been shown that flies and possibly other insects may mechanically transport eggs over considerable distances, having been contaminated during feeding or egg-laying activities in or on the dung (Lawson and Gemmell, 1985).

The survival of the infective egg is influenced by environmental factors, such as humidity and temperature. While eggs may survive for several months under moist conditions and moderate temperatures, desiccation is detrimental and they will only survive a short time when exposed to direct sunlight and dry conditions (Permin and Hansen, 1994). All disease-causing species of Echinococcus are transmitted to intermediate hosts via the ingestion of eggs and are transmitted to definitive hosts by means of eating infected, cyst-containing organs. Humans are accidental intermediate hosts that become infected by handling soil, dirt or animal hair that contains eggs (Eckert et al., 2001).

The number of infective eggs ingested by the intermediate host is therefore, determined by the level of contamination and the infectivity of the eggs. Furthermore, the number of eggs that develop into hydatid cysts is controlled by the immune system of the host (Thompson and Allsopp, 1988). An adult worm resides in the small intestine of a definitive host. Afterwards, gravid proglottids release eggs that are passed in the feces of the definitive host. The egg is then ingested by an intermediate host. The egg then hatches in the small intestine of the intermediate host and releases an oncospheres that penetrates the intestinal wall and moves through the circulatory system into different organs, in particular the liver and lungs. Once it has invaded these organs, the oncospheres develop into a cyst. The cyst then slowly enlarges, creating protoscolices and daughter cysts within the cyst. The definitive host then becomes infected after ingesting the cyst-containing organs of the infected intermediate host. After ingestion, the protoscolices attach to the intestine. They then develop into adult worms and the cycle starts all over again (CDC, 2009). 


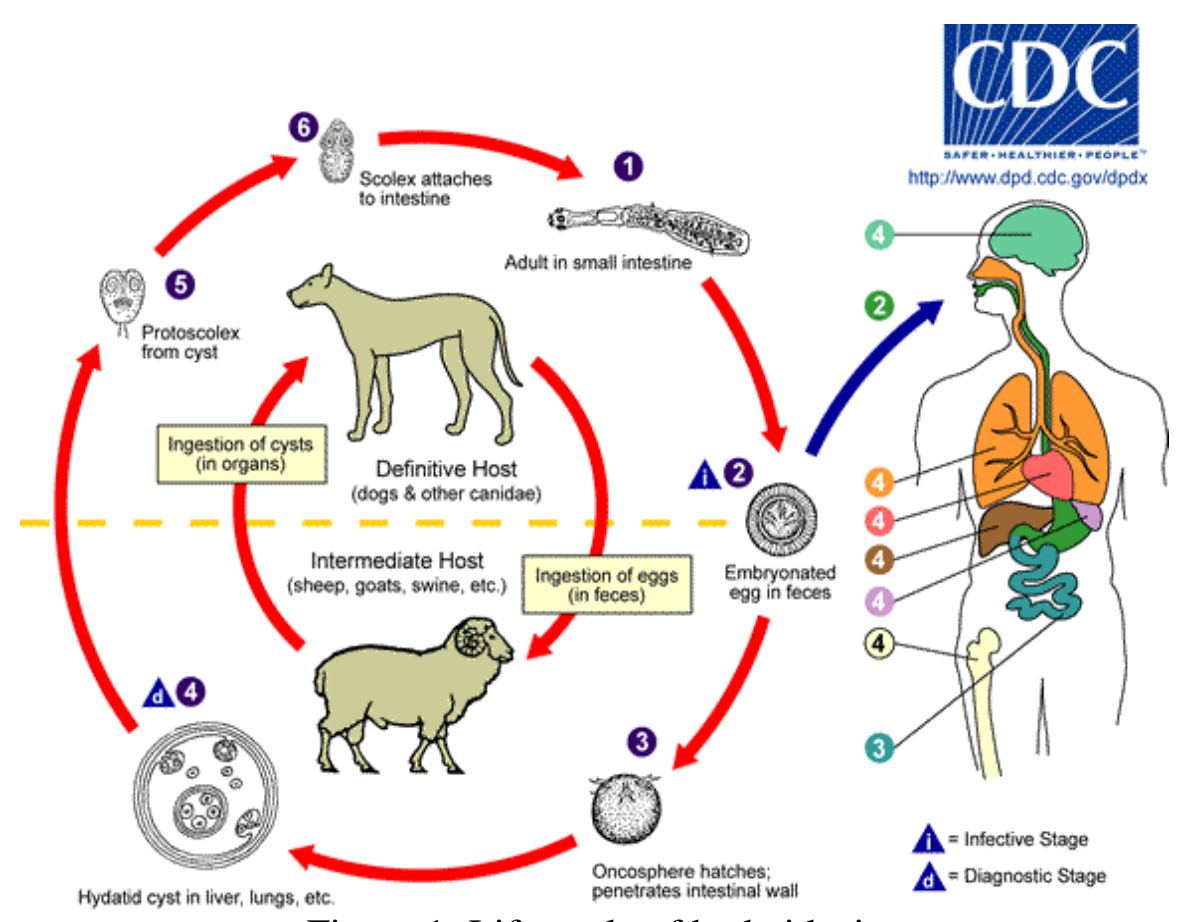

Source: (CDC, 2006)

Figure 1: Life cycle of hydatidosis

The adult Echinococcus is rather harmless to the definitive host, except when it occurs in large numbers, which may cause severe enteritis. The effect of the hydatid cyst on the intermediate host depends on the size and location of the cyst. There are few available data on the clinical effects of the cystic hydatid disease in animals since the cyst is slow in growing and animals are often slaughtered before it manages to create sufficient pressure on the tissue or organs. In humans, the hydatid cyst is normally well tolerated until its development results in pressure on adjacent tissue or organs. The cyst may also burst into the peritoneal or thoracic cavity, which can cause anaphylactic shock or give rise to many new cysts (Eckert et al., 2001).

In the definitive host, a post-mortem examination is the most reliable method of diagnosis. Examination of the feces after using arecoline as a purgative is less reliable, although proglottids in the feces are conclusive. Egg counts are not specific because of the similarity of eggs from other tapeworms of the Taenia family (FAO, 1982). Serological screening has recently proved to be a powerful tool in detecting infected dogs and is superior to the arecoline testing (Gasser et al., 1990). In the intermediate host, diagnosis of hydatidosis is possible through scanning, radiology, serology and postmortem examination. The post-mortem examination of sheep is usually an important component in monitoring the efficiency of control programmes (Permin and Hansen, 1994).

Several anthelmintic drugs have proved to be effective against adult stages of E. granulosus in the final host. The best drug currently available is praziquantel, which exterminates all juvenile and adult Echinococcus from dogs (Schantz, 1982; WHO, 1992). Unfortunately, surgery is the treatment of choice at present, but several of the benzimidazole compounds have been shown to have efficacy against the hydatid cyst in the intermediate host. Long-term treatment with albendazole has a particularly marked effect on the cysts (Morris et al., 1990). While long-term 
treatment with praziquantel only has a limited effect with few changes in the germinal layer of the cyst (Permin and Hansen, 1994).

The epidemiology and control of hydatidosis is often considered to be a veterinary matter since the disease can be regulated by controlling parasites in animals. However, collaboration between veterinarians and public health workers is essential for the successful control of hydatidosis (Eckert et al., 2001). Echinococcosis can be controlled through preventive measures that break the cycle between the definitive and the intermediate host. These measures include dosing dogs, inspecting meat and educating the public on the risk to humans and on avoiding feeding offal to dogs, as well as introducing legislation. The disease can be controlled successfully through health education and appropriate legislation only when people understand the life cycle of the parasite. It is of the utmost importance that the government be involved, through the Ministries of Health, Agriculture and the Interior, for example. So far, the only successful control programmes have been those where the Ministry of Agriculture has been the responsible control authority (Gemmell, 1989).

A number of experiments to induce immunity in dogs through vaccination have been carried out using non-living vaccines such as hydatid cyst fluid, extracts of membranes (adult worms), worm secretions and protoscolices have been used as possible source of a suitable immunogenic, but with limited success (Health and Lightowlers, 1997). Currently there are no human vaccines against any form of Echinococcosis. However, there are studies being conducted that are looking at possible vaccine candidates for an effective human vaccine against Echinococcosis (Dang et al, 2009)

The country has been noted for a high prevalence of hydatid disease Since the 1970s (Bekele, 2010). Moreover, reports of findings from abattoirs in various locations revealed that hydatidosis is wide spread in Ethiopia with great economic and public health significance (Kebede et al, 2009). Moreover, no information is available about the status of hydatidosis in and around Wolayta Soddo in SNNPR. Hence it would be essential to have information on the status of hydatidosis and with regard to its occurrence from different parts of the country to establish appropriate strategy for prevention and control.

Therefore, the objectives of the current study were to:

- Determine the prevalence of hydatidosis in cattle slaughtered at Wolayta town municipal abattoir.

- To characterize of hydatid cyst.

- To recommend relevant control measures.

\section{Materials and Methods}

\subsection{Study Areas}

The study was conducted from November to March, 2012/2013 in Wolayta Zone, at Wolayta Soddo town Municipal Abattoirs, which are located in the Southern Nations Nationality and people's regional state. 
Geographically, Wolayta Zone, Wolayta Soddo town is found 390km southwest of Addis Ababa. It is one of the certified towns of the region with Municipality status. Wolayta Zone is located between 6.40 to $7.10 \mathrm{~N}$ latitude and 37.40 to $38.20 \mathrm{E}$ longitudes and has an altitude of 600-1700 m.a.s.l. It has an area of $4511 \mathrm{Km} 2$ and according to Central Statistical Agency report of 2010, total number of population of the area is about 1,581,650. The main occupation of the rural population is mixing farming practice where by crop and livestock are managed. The livestock population of the zone is 2,261,985 cattle, 1,127,930 sheep, 191,939 goats, 1528,249 chickens, 12,559 horses and 3,035 donkeys (WZFEDD, 2012)

The Zone is classified into three agro ecological zone, among them large proportion is WainaDega (mid-altitude) which is about $56 \%$ of the area; the rest $35 \%$ and $9 \%$ is described as Kola (low altitude), and Dega (high altitude) respectively. The estimated average annual rainfall is 801 to $1600 \mathrm{~mm}$. The rainfall in the Zone is characterized by bimodal distribution pattern and the main rainy season (Maher) is between Junes and continues up to end of September and Belg is from late February to late March/early April. The annual average temperature of the zone is $21.86^{\circ} \mathrm{C}$. The altitude of the zone ranges from 501 to 3000 meter above sea level (WZFEDD, 2012)

Wolayta Municipal Abattoir has a fence, guardroom, lairage, slaughterhouse, and septic tank. The slaughterhouses are built of iron sheet wall and cemented floor. The wall has a facility to hang the carcasses at one side, and the offal and heads at one side. The floor has installed iron rod at the middle for casting animals, while on the opposite side of the floor, where offal and heads are processed, is a drainage tunnel, while on the opposite side the carcasses are hanged on the

\subsection{Study Population}

The studies animals are indigenous local zebu were coming from woredas of Wolayta and Dawuro Zones and adjacent Arba minch and Sidama Zones for slaughtering purpose. During the study period a total of 446 were examined for the presence of hydatid cyst.

\subsection{Study Design}

Cross-sectional study was conducted from November to March, 2012/2013 to collect data on the prevalence and cyst characterization of bovine hydatidosis Wolayta Soddo municipal abattoirs.

\subsection{Sample Size Determination}

Sample size was conducted using random sampling techniques which ensure the sample is evenly distributed across the study population. The sample size was calculated according to Thrusfield (2005). The average is $50 \%$ to be determined with $95 \%$ confidence interval $(95 \% \mathrm{CI})$ and $5 \%$ desired absolute precision $(\mathrm{d}=0.05)$.

$$
\begin{array}{cc}
\mathrm{n}=\frac{1.962(\mathrm{p})(1-\mathrm{p})}{\mathrm{d} 2} \quad \text { where } \quad \begin{array}{l}
\mathrm{n}=\text { Sample size } \\
\mathrm{p}=\text { expected prevalence } \\
\mathrm{d}=\text { desired level of Precision }
\end{array}
\end{array}
$$


Accordingly, based on the above formula the required sample size was 384 . To increase the accuracy of the study, the total number of sample size was increased to 446.

\subsection{Study Methodology}

\subsubsection{Active Abattoir Survey}

Regular visit was made to conduct ante mortem examination of animal's brought for slaughter. This time, individual animal was assessed with regard to their place of origin, sex, age, breed and body condition was recorded. Animals, depending on their body condition were ranked as fat, medium and lean (annex 7. 2). The age of the animals was determined based on dentition and owner information, and grouped in to two: less and greater than five years (Annex 7. 3).

Postmortem examination was carried out by visual inspection, palpation and systematic incision of each visceral organ particularly the lung, liver; spleen, kidney and heart were carried out according to procedures recommended by (FAO, 1994). The cyst was collected from different organs were taken to laboratory to conduct cyst size and fertility and viability tests. All organs harboring hydatid cysts was partially or totally condemned and was judged according to guidelines on meat inspection for developing countries.

\subsubsection{Cyst Characterization}

The total number of hydatid cysts were counted and recorded per affected organ. The cyst burdens were also recorded in correspondence with body condition scoring. Hydatid cyst size was measured by ordinary rulers and classification made based on cyst diameter as small cyst (less than 2cm), medium (2-4cm), large (greater than 4cm) (Dalimi et al., 2002).

\subsubsection{Examination of Cyst and Checking the Fertility and Viability}

The content of cyst was aspirated with the syringe to decrease its pressure and collected in a graduated beaker and the rest of the fluid was then added to it to measure its volume. The content was allowed to stay on incubator for $30 \mathrm{~min}$ at 360c to settle the content and about $10 \mathrm{ml}$ of these sediments was poured to the test tube and centrifuged at $1000 \mathrm{rpm}$ for $3 \mathrm{~min}$ to separate the contents clearly from the liquid part. The supernatant was discarded and the sediment with some fluid was left in the test tubes. The examination was done under objectives $(x 40)$ magnification for the presence/absence of protoscolex. The protoscolices present as white dots on the germinal epithelium or brood capsule or hydatid sands within the suspension, the cyst categorized as fertile. Then the fertile cysts further subjected for viability test. For clear vision a drop of the sediment consisting of protoscolices placed on microscope glass slide and a drop of $0.1 \%$ aqueous eosin solution added and covered by cover slip and observes under microscope (x40), with principle that viable protoscolices exclude the dye while dead ones take it up (Macpherson, 1985, Kebede et al., 2008, Gebremeskel and Kalayou, 2009). Furthermore, fertile cysts were characterized their smooth inner lining usually with slightly turbid fluid in its content. The infertile cyst classified as sterile or calcified. Typical calcified cysts produce a gritty sound feeling upon incision (Tsimoyiannis et al., 2000). 


\subsection{Data Management and Analysis}

The data obtained from ant mortem and postmortem finding and characterization of cysts was coded and uploaded in to the Microsoft excel 2007 spread sheet computer program and analyzed using Stata11version are used to compare the infection status with regard to the hypothesized risk factors like origin, age, body condition score, and cyst characteristics like cyst size (small, medium and large), cyst type (fertile, sterile, degenerated or calcified) and protoscolices viability (viable and nonviable).

\section{Results}

\subsection{Total Prevalence of Bovine Hydatidosis}

Out a total of 446 local zebu cattle breed were examined at Wolayta Soddo municipal abattoir, 50 cattle $(11.21 \%)$ were harboring hydatid cysts in their visceral organs.

Table 1: Total prevalence of hydatid cyst

Examined animals Positive animals Negative animals

\begin{tabular}{llll}
\hline No & $\%$ & No & $\%$
\end{tabular}

$\begin{array}{lllll}446 & 50 & 11.21 & 396 & 88.79\end{array}$

Table 2: Distribution of Hydatid Cyst in different organs of cattle slaughtered at Wolayta Soddo Municipal Abattoir, SNNPR.

\begin{tabular}{cccc}
\hline Organs & No of infected organs & Relative Prevalence (\%) & Total \\
\hline Lung & 26 & 50.0 & 26 \\
Liver & 14 & 26.92 & 14 \\
Kidney & 3 & 5.77 & 3 \\
Spleen & 5 & 9.62 & 5 \\
Heart & 4 & 7.69 & 4 \\
Total & 52 & 100 & 52 \\
\hline
\end{tabular}

\subsection{Characterization of Cyst Size}

The total counts with respect to size in each organ were indicated table 3 . A total of 52 cysts with complete cyst size data were collected from 50 infected animals. Out of a total hydatid cyst recovered in cattle $26.69 \%(14 / 52)$ were large, $34.62 \%$ (18/52) were medium and $38.46 \%$ (20/52) were small cysts (Table 3 ). The rate of occurrence of large and medium size cysts were found in lung where as small size cysts were found in liver. 
Table 3: Characterization of cyst size in relation with organ involvement in infected cattle in Wolayta Soddo Municipal Abattoir, SNNPR.

\begin{tabular}{|c|c|c|c|c|c|c|c|}
\hline \multirow[t]{2}{*}{ Organs } & \multicolumn{2}{|c|}{ Large cyst } & \multicolumn{2}{|c|}{ Medium cyst } & \multicolumn{2}{|c|}{ Small cyst } & \multirow[t]{2}{*}{ Total } \\
\hline & No & $\%$ & No & $\%$ & No & $\%$ & \\
\hline Lung & 12 & 46.15 & 10 & 38.46 & 4 & 15.38 & 26 \\
\hline Liver & 2 & 14.29 & 3 & 21.43 & 9 & 64.28 & 14 \\
\hline Kidney & - & - & - & - & 3 & 100 & 3 \\
\hline Spleen & - & - & 4 & 80 & 1 & 20 & 5 \\
\hline Heart & - & - & 1 & 25 & 3 & 75 & 4 \\
\hline Total & 14 & 26.69 & 18 & 34.62 & 20 & 38.46 & \\
\hline
\end{tabular}

\subsection{Cyst Fertility, Sterility and Viability}

Out of 52 cysts examined, with complete cyst size data were collected from 52 infected organs $67.31 \%(35 / 52)$ were sterile cyst, $23.08 \%(12 / 52)$ were calcified cyst and $9.62 \%(5 / 52)$ fertile cyst of which $20 \%(1 / 5)$ were viable and $80 \%$ (4/5) were nonviable cysts. The cyst condition by organ involvement was found to be $73.08 \%$ (19/26) were sterile, $15.38 \%(4 / 26)$ were fertile of which $25 \%$ (1/4) were viable and $75 \%$ (3/4) were nonviable, and $11.54 \%(3 / 26)$ were calcified in the lung. In liver, $7.14 \%(1 / 14)$ were fertile of which $100 \%$ were nonviable and $42.86 \%(6 / 14)$ were sterile, and $50 \%(7 / 14)$ were calcified. In kidney, 66.67\% (2/3) were sterile and 33.33\% $(1 / 3)$ were calcified and in spleen, $80 \%(4 / 5)$ were sterile, $20 \%(1 / 5)$ were calcified. All cysts in the hearts were sterile (Table: 4 ).

Table 4: Fertility rates and viability of protoscolices of fertile cysts recovered from different organs of cattle slaughtered at Wolayta Soddo Municipal Abattoir, SNNPR.

\begin{tabular}{|c|c|c|c|c|c|c|c|c|c|c|c|}
\hline \multirow[t]{3}{*}{ Organs } & \multicolumn{4}{|c|}{ Fertile cysts } & \multicolumn{2}{|c|}{ Sub total } & \multicolumn{2}{|c|}{ Sterile cyst } & \multicolumn{2}{|c|}{ Calcified cyst } & \multirow[t]{3}{*}{ Total } \\
\hline & \multicolumn{2}{|c|}{ Viable } & \multicolumn{2}{|c|}{ Nonviable } & & & & & & & \\
\hline & № & $\%$ & № & $\%$ & № & $\%$ & No & $\%$ & № & $\%$ & \\
\hline Lung & 1 & 25 & 3 & 75 & 4 & 15.38 & 19 & 73.08 & 3 & 11.54 & 26 \\
\hline Liver & - & - & 1 & 100 & 1 & 7.14 & 6 & 42.86 & 7 & 50 & 14 \\
\hline Kidney & - & - & - & - & - & - & 2 & 66.67 & 1 & 33.33 & 3 \\
\hline
\end{tabular}




\begin{tabular}{lccccccccccc}
\hline Spleen & - & - & - & - & - & - & 4 & 80 & 1 & 20 & 5 \\
Heart & - & - & - & - & - & - & 4 & 100 & - & - & 4 \\
Total & 1 & 20 & 4 & 80 & 5 & 9.62 & 35 & 67.31 & 12 & 23.08 & 52
\end{tabular}

\subsection{Body Condition Score and Hydatid Cyst Prevalence}

Assessment of hydatid cyst count and infected organs with body condition scoring in cattle revealed that there was statically significant difference $(\mathrm{p}<0.05)$ (Table 5).

Table 5: Relationship between body condition and cyst count in infected cattle slaughtered at Wolayta Soddo Municipal Abattoir, SNNPR.

\begin{tabular}{|c|c|c|c|c|c|c|c|c|c|}
\hline \multirow[t]{2}{*}{ BCS } & \multirow{2}{*}{$\begin{array}{l}\text { Examined } \\
\text { Animals }\end{array}$} & \multirow{2}{*}{$\begin{array}{l}\text { Positive } \\
\text { Animals }\end{array}$} & \multirow[t]{2}{*}{$\%$} & \multicolumn{5}{|c|}{ № of affected organs and cysts } & \multirow[t]{2}{*}{ Total } \\
\hline & & & & Lung & Liver & Kidney & spleen & Heart & \\
\hline Medium & 210 & 33 & 15.71 & 17 & 11 & 1 & 3 & 2 & 34 \\
\hline Fat & 236 & 17 & 7.20 & 9 & 3 & 2 & 2 & 2 & 18 \\
\hline Total & 446 & 50 & 11.21 & 26 & 14 & 3 & 5 & 4 & 52 \\
\hline
\end{tabular}

\subsection{Place of Origin and Hydatid Cyst Prevalence}

Out of 446 cattle examined hydatid cyst count and infected organs regarding to place of origin in cattle shown that no significant difference $(\mathrm{p}>0.05)$ was observed in highland (11.27\%), midland (11.11\%) and lowland (13.33\%) (Table 6).

Table 6: Relationship between place of origin and cyst count in infected cattle slaughtered at Wolayta Soddo Municipal Abattoir, SNNPR.

\begin{tabular}{|c|c|c|c|c|c|c|c|c|c|}
\hline \multirow[t]{2}{*}{ origin } & \multirow{2}{*}{$\begin{array}{l}\text { Examined } \\
\text { Animals }\end{array}$} & \multirow{2}{*}{$\begin{array}{l}\text { Positive } \\
\text { Animals }\end{array}$} & \multirow[t]{2}{*}{$\%$} & \multicolumn{5}{|c|}{ № of affected organs and cysts } & \multirow[t]{2}{*}{ Total } \\
\hline & & & & Lung & Liver & Kidney & spleen & Heart & \\
\hline Low & 15 & 2 & 13.33 & 1 & 1 & 0 & 0 & 0 & 2 \\
\hline Mid & 243 & 27 & 11.11 & 13 & 8 & 1 & 3 & 2 & 27 \\
\hline High & 188 & 21 & 11.17 & 12 & 5 & 2 & 2 & 2 & 23 \\
\hline
\end{tabular}




\begin{tabular}{llllllllll}
\hline Total & 446 & 50 & 11.21 & 26 & 14 & 3 & 5 & 4 & 52
\end{tabular}

$\mathrm{Ch} 2=0.0706, \mathrm{P}$-value $=0.965$

\subsection{Age Determination and Cyst Condition}

Out of 446 cattle examined, hydatid cysts count and infected organs with respect to the age in the cattle (Table: 7). The difference in the prevalence of the hydatid disease among less than 5 years and greater than 5 years were conducted in abattoir, there was no significant difference observed $(\mathrm{p}>0.05)$.

Table 7: Relationship between age and cyst count in infected cattle slaughtered at Wolayta Soddo Municipal Abattoir, SNNPR.

\begin{tabular}{|c|c|c|c|c|c|c|c|c|c|}
\hline \multirow[t]{2}{*}{ Age } & \multirow{2}{*}{$\begin{array}{l}\text { Examined } \\
\text { Animals }\end{array}$} & \multirow{2}{*}{$\begin{array}{l}\text { Positive } \\
\text { Animals }\end{array}$} & \multirow[t]{2}{*}{$\%$} & \multicolumn{5}{|c|}{ № of affected organs and cysts } & \multirow[t]{2}{*}{ Total } \\
\hline & & & & Lung & Liver & Kidney & spleen & Heart & \\
\hline$<5$ years & 143 & 10 & 6.99 & 7 & 1 & - & 2 & - & 10 \\
\hline$>5$ years & 303 & 40 & 13.20 & 19 & 13 & 3 & 3 & 4 & 42 \\
\hline Total & 446 & 50 & 11.21 & 26 & 14 & 3 & 5 & 4 & 52 \\
\hline
\end{tabular}

Chi2 $=0.7469, \mathrm{P}-$ value $=0.688$

\section{Discussion}

The culture and tradition of the people in the study area favor the keeping of dogs in peri urban areas (urban and rural households) often in close association with the family and farm animals. Almost all of cattle owners, shepherds and urban dwellers keep at least one dog for the purpose of safeguarding their properties from wild carnivores and thieves. In general, backyard slaughtering practices during holidays, ceremonies and other feasts. During backyard slaughtering, meat inspection is not conducted and the offals are often given to pets or dispose of in the backyard. These and other socioeconomic realities in the areas studied are considered to be conducive to existence of hydatid diseases in the study area.

On the basis of data collected from Wolayta Soddo Municipal Abattoir, the prevalence of bovine hydatidosis during the study period was found to be $11.21 \%$. In general terms, throughout the world, there had been different magnitude records of hydatidosis in cattle with low, medium and high rates of occurrences. In Ethiopia, various authors reported the occurrence of the disease in nation. The current finding was in an agreement with the findings in Gonder 8.08\% (Tamene, 1986), Western Iran 16.4\% (Hafez and Yamen, 2002), Wolayita Sodo 16.85\% (Bekele and Butako, 2010). The result of this study is lower as compared to the studies among which $31.9 \%$ in Nekemite (Feyessa, 1987), 36.3\% in Addis Ababa (Yimer et al., 2002), 52.69\% in Hawassa 
(Regassa et al., 2010), 54.8\% in Arsi (Alemayehu, 1990) and 46.5\% in Debre Zeit and 25.7\% in South Omo (Jobre et al., 1996). This may be described to difference in environmental conditions, livestock intensity and livestock movement that contribute to the differences in prevalence rates (Njoroge et al., 2002).

Regarding cyst distribution, the lung was mostly affected followed by liver. The reason for this phenomenon probably the liver capillary is dilated and most oncospheres pass directly to the lung, the study indicated that most of cysts identified in cattle tended to be concentrated in great number in lung and liver, with prevalence of $50.0 \%$ and $26.92 \%$ respectively. There was also lower prevalence in kidney $(5.77 \%)$, spleen $(9.62 \%)$ and heart $(7.69 \%)$. This is explained by the fact that lung and liver possess the first great capillary sites encountered by the migrating Echinococcus oncospheres (hexacanth embryo) which adopt the portal route and primary negotiate hepatic and pulmonary filtering system sequentially before any other peripheral organs is involved (Scantz, 1982).

The reason for higher percentage of large cysts in the lungs is due to softer consistency of the lung, while the higher yield of calcified cysts in liver could be attributed to relatively higher reticuloendothelial cells and abundant connective tissue reaction of the organs. The high proportion of small cysts may be due to immunological response of the host, which might preclude expansion of cyst size (Torgerson et al., 1998; Larrieu et al., 2001).

With regard to fertility and viability of cysts, the findings of $67.31 \%$ sterile, $9.62 \%$ fertile $(20 \%$ viable and $80 \%$ nonviable) and $23.08 \%$ calcified cysts in cattle may generally imply that most of the cyst in cattle are sterile (infertile). Similarly, in Britain up to $90 \%$ of total cysts from cattle were reported to be sterile. The variation in fertility rate in different geographical zone could be the difference in strain of Echinococcus (Arene, 1985). The fertility of hydatid cysts in the intermediate hosts is genotype dependent. Cattle infected with G5 had more than $90 \%$ fertile cysts (Eckert and Thompson, 1997). In contrast, cysts from cattle infected with G1, G3 genotypes of E. granulosus were all sterile (Rinaldi et al., 2008). No data is available with regard to types of strains in the country so far. Information about strain differentiation is only available from Kenya and Sudan in the eastern part of Africa (Magambo, et al., 2006).

The fertility rate among the organs the highest in the lung, this variation might be due to the differences between tissue resistances of the organs. This is due to the relative softer consistency of lung tissue that allows easier development of the cyst and the fertility (Himonas, 1987). The fact that a single strain generates fertile or sterile cysts in different host species would indicate natural immunity in some hosts. Thus, preventing the development and growth protoscolices and maintaining the cyst in an infertile (Zhang et al., 2003). The proportion of animals with fertile, viable cysts is an important indicator of the significance of a species as an intermediate hosts. Viable cysts may play an active role in disease transmission.

With regard to body condition scoring, out of 446 cattle examined, hydatid cysts count and infected organs to the body condition scoring in the cattle shown that medium 210(15.71\%) had higher number of hydatid cyst counts than fat, though higher cyst number were observed in medium body condition animals, fat cattle were harboring 236 (7.20\%) cysts in different organs. 
There is no significant variation was observed regards to body condition score (Bekele and Butako, 2010; Regassa et al., 2010), but in this study there is significant differences $(\mathrm{P}<0.05)$

There is low prevalence of hydatid cyst was observed during November and December, but after the government takes action all over the country to control illegal increment of the price associated with salary increment at the end of January. Hence, meat price was reduced in the Wolayta town. This results the income of the butchers was decreased because of the buying the animals by high price and selling of meat with low price. Due to that to compensate their income, they slaughter medium body condition animals. After medium body condition animals slaughtered, increased the prevalence of hydatid cyst in slaughtered animals. This may be hydatidosis causes reduction in weight gain and growth. Symptoms can occur a long time after infection, sometimes months or years later and may not be symptoms at all (Over et al., 2004). This asymptomatic and chronic nature of the disease causes unexplained weight losses.

Early estimation of indirect losses like reduction of carcass weight is difficult due to lack of standard methods for early estimating the cost of infection and to differentiate among animal population sizes, disease prevalence, inherent socioeconomic patterns and period of evaluation in the Ethiopia. There is usually no early parasitological evidence for the presence of cysts in organs or tissues and in most cases the early stage of infections are asymptomatic. Over the last decade diagnosis of hydatid disease was improved due to the use of imaging techniques including ultrasonography, computed tomography (CT scanning) and magnetic resonance imaging (MSI) supported by immunological assays for confirmation of clinical diagnosis (Zhang et al., 2003). The prevalence of hydatidosis in livestock was carried out based on the reported number of infected animals identified through routine postmortem examination in all slaughter houses in Ethiopia. Official figures on animal hydatidosis are subsequently submitted to many Ethiopian regions on trends and sources of zoonosis after postmortem examination, but there is no surveillance on asymptomatic alive animals.

\section{Conclusion and Recommendations}

Hydatidosis causes a considerable loss to livestock industry. In this study relatively high prevalence of hydatidosis was recorded in cattle. In the study area there is no proper origin and organs condemned recording system by specific disease type, so it is difficult to contribute in the control by feedback mechanism by reporting the prevalence of the disease to the area that animals were originated and what type of is prevalent. Presence of backyard slaughtering system, increase the number of stray dogs, the relation existing between livestock and pet animals and nil emphasis given to the health of pet animals in the area were the main factors that may have contributed to the prevalence of the diseases. Though large number of cysts in cattle was sterile, the presence of higher proportion of viable cysts among the fertile cysts indicates cattle still the important intermediate hosts in the country.

Based on the results of the presence survey, the following recommendations are forwarded:

- Initiate and involves pertinent agencies, such as, public health, veterinary and educational institution to participate directly by providing appropriate administrative, legal, technical, and economic support to control.

- Proper disposal of all condemned offals. 
- Control of stray dogs.

- Regular deworming of dogs with anthelmintic.

- Awareness creation programs should be launched for the butchers, abattoir workers, meat sellers and dog owners as to the danger of the hydatid cyst to humans and animal hydatidosis.

\section{Acknowledgements}

First, I would like to thank the almighty of lord, without whose grace I would have not been able to do this study. Invariably I would like to express my deepest gratitude to Wolayta Soddo Municipal Abattoir workers for their appreciable guidance, advice and help during my work in Abattoir.

Finally, a deep sense of gratitude and sincere thanks to my sister, Mom and all my family for their critical financial and moral support in my school life up to now.

\section{Annexes}

\subsection{Postmortem Examination Recording Format}

\subsubsection{Abattoir Work}

\begin{tabular}{|c|c|c|c|c|c|c|c|c|c|c|c|c|c|}
\hline \multirow[t]{2}{*}{ Date } & \multirow{2}{*}{$\begin{array}{l}\text { Owner } \\
\text { Name }\end{array}$} & \multirow[t]{2}{*}{ origin } & \multirow[t]{2}{*}{ spp } & \multirow[t]{2}{*}{ breed } & \multirow[t]{2}{*}{ sex } & \multirow[t]{2}{*}{ age } & \multirow[t]{2}{*}{ bcs } & \multicolumn{5}{|c|}{ Major organs inspected } & \multirow{2}{*}{$\begin{array}{l}\text { Judge } \\
\text { ment }\end{array}$} \\
\hline & & & & & & & & lung & liver & kidney & spleen & heart & \\
\hline & & & & & & & & & & & & & \\
\hline & & & & & & & & & & & & & \\
\hline & & & & & & & & & & & & & \\
\hline & & & & & & & & & & & & & \\
\hline
\end{tabular}

Where: - spp: species, bcs: body condition score.

\subsubsection{Laboratory Work}

\begin{tabular}{|l|l|l|l|l|l|l|l|}
\hline \multicolumn{2}{|c|}{ Size of cysts } & \multicolumn{3}{c|}{ Type of cysts } & \multicolumn{2}{c|}{ Viability of cysts } \\
\hline Large & medium & small & fertile & sterile & calcified & viable & nonviable \\
\hline & & & & & & & \\
\hline
\end{tabular}




\begin{tabular}{|l|l|l|l|l|l|l|l|}
\hline & & & & & & & \\
\hline & & & & & & & \\
\hline
\end{tabular}

\subsection{Description of Body Condition Score}

\begin{tabular}{|c|c|c|}
\hline Score & Condition & Features \\
\hline 1 & $\mathrm{P}^{-}$ & Marked emaciation (animal condemned at ante mortem examination) \\
\hline 2 & $\mathrm{P}$ & Transverse process project prominently, neural spines appears sharply \\
\hline 3 & $\mathrm{P}^{+}$ & $\begin{array}{l}\text { Individual dorsal spines are pointed to the touch, hip pins, tail, head ribs are } \\
\text { prominent. Transverse process visible, usually individually. }\end{array}$ \\
\hline 4 & $\mathrm{M}^{-}$ & $\begin{array}{l}\text { Ribs, hips and spines clearly visible muscle mass between hook of spines } \\
\text { slightly concave and slightly more flesh above the transverse process }\end{array}$ \\
\hline 5 & $\mathrm{M}$ & Ribs usually visible little fat cover dorsal spines barely visible \\
\hline 6 & $\mathrm{M}^{+}$ & $\begin{array}{l}\text { All smooth and well covered, dorsal spine cannot be seen, but are easily } \\
\text { felt. }\end{array}$ \\
\hline 7 & $\mathrm{G}^{-}$ & $\begin{array}{l}\text { All smooth and well covered, but fat deposits are not marked, dorsal spines } \\
\text { can be felt with firm pressure but rounded rather than Sharpe. }\end{array}$ \\
\hline 8 & G & $\begin{array}{l}\text { Fat cover in critical areas can be seen and felt, transverse process cannot be } \\
\text { seen. }\end{array}$ \\
\hline 9 & $\mathrm{G}^{+}$ & $\begin{array}{l}\text { Heavy deposited of fat clearly visible on tail, head, brisket and dorsal spine, } \\
\text { ribs, hook and spines fully covered and cannot be felt even with firm } \\
\text { pressure. }\end{array}$ \\
\hline
\end{tabular}

Source: Nicholson and Butterworth, (1986).

Note: 1, 2 and 3 are lean body condition, 4, 5 and 6 are medium body condition and 7, 8 and 9 are good body condition 


\subsection{Age Determination}

\begin{tabular}{|l|l|}
\hline Age (years) & Teeth \\
\hline $1.5-2$ & I1 erupts \\
\hline $2-2.5$ & I2 erupts \\
\hline 3 & I3 erupts \\
\hline $3.5-4$ & I4 erupts \\
\hline 5 & All incisors are wear \\
\hline 6 & I1 is leveled and the neck has emerged from the gum \\
\hline 7 & I2 is leveled and the neck is visible \\
\hline 8 & I3 is leveled and the neck is visible and it may leveled \\
\hline 9 & I4 is leveled and the neck is visible \\
\hline $10-11$ & The dental star is square \\
\hline Source & \\
\hline
\end{tabular}

Source: http://wapedia.mob:/en/cattle-age-determination.htm/

\section{References}

[1] Alemayehu, L. (1990). 'Prevalence of hydatidosis in cattle, sheep, goats and Echinococcosis in Dogs in Arsi. DVM thesis, Faculty of Veterinary Medicine, Addis Ababa, Ethiopia. Pp. 26.

[2] Arene, F. O. I. (1985). "The prevalence of hydatidosis in domestic livestock in Niger Delta". Trop. Anim. Health Prod. 7, 3-4.

[3] Bekele, J. and Butako, B. (2010). "Occurrence and Financial Loss Assessment of Cystic Echinococcosis (Hydatidosis) in cattle slaughtered at Wolayta Sodo Municipal Abattoir, southern Ethiopia”. Trop. Anim. Health prod, 43(1),221-228. 
[4] Wolayta Zone Agricultural and Development Department, BMZARDD, (2006). "Basic data of Wolayta Zone Agricultural Development". Unpublished.

[5] Berhe, B. (2009). "Survey on hydatidosis in Tigray region of Ethiopia". Trop. Anim. Prod. 41, 1347-1352.

[6] Bureau of Finance and Economic Development Division of Statistics and Population WZFEDDSP. (2007). Unpublished. "Basic data of Wolayta Zone Agricultural Development".

[7] Center for Disease Control, CDC. (2006). "Parasite Image Library: Echinococcosis." DPDx. CDC, Web. 20 February 2010. Elsevier. Pp. 224-231.

[8] Center for Disease Control, CDC. (2009). "Parasites and Health: Echinococcosis." DPDx.CDC, Web. 5 February 2010. Elsevier. Pp. 32-33.

[9] Central Statistical Agency, CSA. (2009). "Agricultural sample survey 2008-09 (2001 E.C.). Volume II. Report on livestock and livestock characteristics (private peasant holdings)". Statistical bulletin 3, Addis Ababa, Ethiopia. Pp. 188.

[10] Dalmi, M., Motamedi, G. H., Mohammedian B. et al., (2002). "Echinococcosis/ hydatidosis in Western Iran". Vet. Parasitol. 105, 161-171.

[11] Dang, Zhisheng E. and Bigatti, R. (2009). "Evaluation of Echinococcus multilocularis Tetraspanins as Vaccine Candidates against Primary Alveolar Echinococcosis". Vaccine 27(52), 7339-7345. Web. 25 February 2010.

[12] Eckert, J., Gemmell, M. A., Meslin, F. X. and Pawłowski, Z. S. (2001). "WHO/OIE Manual on Echinococcosis in Humans and Animals: a Public Health Problem of Global Concern". World Organization for Animal Health (Office International des Epizooties) and World Health Organization.

[13] Eckert, Johannes, and Deplazes, P. (2004). "Biological, Epidemiological, and Clinical Aspects of Echinococcosis, a Zoonosis of Increasing Concern." Clin. Microbiol. Rew. 17, 107-135. Web. 5 February 2010.

[14] FAO (1994). "Guidelines for Echinococcosis surveillance, prevention and control”. FAO, Rome, No. $29,47$.

[15] FAO, (1982). "Echinococcosis/Hydatidosis: surveillance, prevention and control. FAO/UNEP/WHO guidelines". FAO, Rome. Anim. Prod. and Health Paper. 29, 50-54.

[16] Feyessa, R. (1987). "Prevalence of hydatidosis at Nekemite municipality slaughterhouse. DVM thesis". Faculty of Veterinary Medicine, Addis Ababa, Ethiopia pp.16.

[17] Gasser, R. B., Lightowlers, M. W., Rickard, M. D. \& Dawkins, H. J. S. (1990). "Serological screening of farm dogs for Echinococcus Granulosus infection in an endemic region". Aust. Vet. J. 67(4), 145-147.

[18] Gebremeskel, B, and Kalayou, S, (2009). "Prevalence, viability and fertility study of bovine cystic Echinococosis in Mekele city, Northern Ethiopia". Revenue Med. Vet. 160, 92 - 97.

[19] Gemmell, M. A. \& Lawson, J. R. (1986). "The epidemiology and control of hydatid disease". In R.C.A. Thompson, Ed. The biology of Echinococcus and hydatid disease, Pp. 1\&9-216. London, UK, George Allen and Unwin.

[20] Gemmell, M. A. (1989). "Hydatidosis control: a global view". Aust. Vet. J. 55, 118-124.

[21] Gemmell, M. A., Roberts, M. G., Beard, T. C., Campano, D. S., Lawson, J. R. and Nonnemarker, J. M. (2001). "Control of Echinococcosis in WHO/OIE Manual on Echinococcosis in Humans and Animals: a Public Health Problem of Global Concern. World Organization for Animal Health (Office International des Epizooties), Paris and World Health Organization, Geneva".

[22] Hafez, A. and Yamen, A. (2002). "Echinococcus/hydatidosis in western Iran". Vet. Parasitol. 30, 161-171.

[23] Health, D. D. and Lightowlers, B. (1997). "Prevalence of Echinococcus granulosus in selected area of North Africa cattle". Rev. Med. Pp. 123-134.

[24] Himonas, C. (1987). "The fertility of hydatid cysts in food animals in Greece. Helminth Zoonoses". Amsterdam, The Nether Lands: Martinus Nijh publishers. Pp. 344. 
[25] Jobre, Y., Labago, F., Tirone, G., Abebe, G. and Dorchies, P. (1996). "Hydatidosis in three selected sites in Ethiopia. An assessment trial on its prevalence, economic and public health significance'. Rev. Med. Vet. 147, 797-804.

[26] John, D. T. and William A. P. (2006). "Markell and Voge's Medical Parasitology". 9th ed. St. Louis, MI: Saunders Elsevier. pp. 224-231.

[27] Kebede, N., Mitiku, A. and Tilahun, G. (2008). "Hydatidosis of slaughter animals in Bahir Dar abattoir, north western Ethiopia". Trop. Anim. Health prod. 41, 43-50.

[28] Kebede, W., Hagos, A., Girma, Z., Labago, F. (2009). "Echnococcosis / hydatidosis: its prevalence, economic and public health significance in Tigray region, north Ethiopia". Trop. Anim. Health Prod. 41, 865-871.

[29] Larieu, E., Costa, M. T., Cantoni, G. et al., (2001). "Ovine Echinococcus transmission dynamics in the province of Rio Negro, Argentina, 1980-1999". Vet. Parasitol. 98, 263-272.

[30] Lawson, J. R. \& Gemmell, M. A. (1985). "The potential role of blowflies in the transmission of Taenia tapeworm eggs". Parasitol. 91, 129-143.

[31] Macpherson, C. N. (1985). "Epidemiology of hydatid disease in Kenya: a study of domesticated intermediate hosts in Masai land”. Trans R soc Trop. Med. Hyg. 79, 193-195.

[32] Macpherson, C., Zeyhle, E. and Roming, T. (1985). "An Echinococcosis plot control program for northwest turcana, Kenya". Annuals of Trop. Med. Parasitol. 78, 188-192.

[33] Magambo, J., Njoroge, E., and Zeyhle, E. 2006. "Epidemiology and control of Echinococcosis in sub-Saharan Africa”. Parasitol. Int. 104, 175-179

[34] McManus, D. P. \& Smyth, J. D. (1986). "Hydatidosis: Changing Concepts in Epidemiology and Speciation". Mandell, Gerald, L. Mandell, Douglas, and Bennett's Principles and Practice of Infectious Diseases. 7th ed. Philadelphia, PA: Elsevier Inc., 2010. Ch. 290. Parasitol. Today, 2(6), 163-168.

[35] Morris, D. L., Richards, K. S., Clarkson, M. J. and Taylor, D. H. (1990). "Comparison of albendazole and praziquantel therapy of Echinococcus granulosus in naturally infected sheep". Ve.t Parasitol. 36, 83-90.

[36] Nicholson, M. J. and Butterworth, M.H. 1986. "A Guide to Condition Scoring of Zebu Cattle". International Livestock Center. Pp. 44.

[37] Njoroge, E. M., Mbithi, P. M. F., Gathuma, J. M., Wachira, T. M., Gathura, T. M. and Magambo, J. K. 2002. "A study of cystic echinococcosis in slaughtered animals in three selected area of northern Turkana, Kenya". Vet. Parasitol, 194, 85-91.

[38] Over, H. J., Jansen, J. and van Olm, P. W. (2004). "Distribution and impact of helminth diseases of livestock in developing countries". FAO Anim. Prod. and Health, 96, 23-25.

[39] Permin, A. and Hansen, J. W. (1994). "Review of echinococcosis/hydatidosis: a zoonotic parasitic disease". World Anim. Rew. 78, 1994/1

[40] Raush, R. L. (1986). "Lifecycle patterns and geographic distribution of Echinococcus species". In R.C.A. Thompson, ed. The biology of Echinococcus and hydatid disease. Pp. 44-80. London, UK, George Allen and Unwin.

[41] Rinaldi, E. M., Maurelli, M.P., Veneziano,v., Capuano, F., Perugini, A. G. and Cringoli, S. (2008). "The role of cattle in the epidemiology of Echinococcus granulosus in an endemic area of southern Italy". Parasitol. Res. 103, 175-179.

[42] Schantz, P. M. (1982). "Echinococcosis". In L. Jacobs \& P. Arambulo, eds. CRC handbook series in zoonoses. Pp. 112.

[43] Schantz, P. M. (1990). "Parasitic zoonoses in perspective”. Int. J. Parasitol., 21(2): 165-166.

[44] Soulsby, E. J. L. (1982). "Helminths, arthropods and protozoa of domesticated animals", 7th ed. Pp. 119-127.

[45] Soulsby, E. J. L. (1986). "Helminthes, arthropods and protozoa of domesticated animals", 7th ed. Pp. 432. The English language Book society, Bailliere Tindall, London.

[46] Tamene, M. (1986). "A preliminary study on Echinocosis/Hydatidosis of live stock (cattle, sheep and goats) in Gonder Administrative Region”. DVM thesis, FVM, Debre Zeit Ethiopia. 
[47] Thompson, R. C. A. \& Allsopp, C. E. (1988). "Hydatidosis: veterinary perspectives and annotated bibliography".

[48] Thrusfield (2005). "Veterinary epidemiology 3rd Edition, United Kingdom". Blackwell sciences Ltd. Pp. 626.

[49] Torgerson, P. R., Williams, D. H. and Shehada, A. (1998). "Modeling the prevalence of Echinococcus and Taenia species in small ruminants of different ages in Jordan". Vet. Parasitol, $79,35-51$.

[50] Tsimoyiannis, E. C., Siakas, P., Glantzounis, G., Tsimoyiannis, J. C., Karayiani, M., Gossios, K. J. (1985). "Intracystic pressure and viability in hydatid disease of the liver". In surg. 85, 234-236

[51] WHO. (1992). "Report of the WHO Working Group Meeting on Clinical Medicine and Chemotherapy of Alveolar and Cystic Echinococcosis". WHO/CDS/VP, H 93, 118.

[52] WZFEDD, 2012. "Wolaita Zone Socio-Economic information. Wolaita Zone Finance and Economic Development Department, Unpublished". May 2012.

[53] Yimer, E., Beyene, M., Woldemichael, T., Zewdie, B. and Bekele, A. (2002). "Prevalence of hydatidosis in animals slaughtered at Addis Ababa abattoir and dog echinococcosis in Addis Ababa city". Pp. 4.

[54] Zhang, W., Li, J. and McManus, D. P. (2003). "Concepts in immunology and diagnosis of hydatid disease', Clin. Microbiol. Rew. Pp. 18-36.

*Corresponding author.

E-mail address: atishabe.dvm@gmail.com 